\title{
THE EPIDEMIC OF MUMPS AT CAMP WHEELER, OCTOBER, 1917-MARCH, $1918 *$
}

\author{
LIEUT. M. J. RADIN, M. R. C. \\ CAMP WHEELER, GA.
}

It is through the kindness and courtesy of Maj. Joseph Sailer, M. R. C., Chief of Medical Service at the Base Hospital, Camp Wheeler, Georgia, that this paper is presented. Methods of procedure, arrangement of the work and inspiration for a rather monotonous task were all drawn from him by the various ward surgeons who have treated mumps. It is due to him alone - and this cannot be too clearly stated - that a stupid and insignificant disease became interesting.

Patients with mumps have occupied almost half of the hospital for three months. An epidemic of such volume raises mumps to the dignity of a disease. Of approximately 18,000 men in the Thirty-First Division, there were 5,756 cases, an incidence of 32 per cent. Every third man in the division, in other words, has had mumps. Of 13,638 total admissions to the hospital to March, 1918, almost one half were mumps - to be exact, 42.2 per cent. Sporadic cases occurred from October 17, 1917, when the first patient was admitted, to November 20, when the epidemic started with 18 admissions. The next increase was on December 3, an interval of two weeks, on which day there were 46 admissions. The third increase occurred December 14, ten days later, when there were 86 admissions. The fourth rise was on December 27, with 133 admissions, and the final increase to the apex of the epidemic was on January 15, on which day there were 140 admissions. The total admissions on this day - all diseases - was 194. There were 624 cases of mumps in the hospital at one time, December 30 . Corresponding falls occurred in the admission rate.

It is regrettable that such a slight, and, in a measure, preventable, disease has occupied so much time, energy and material. Lieutenant Hathcock estimates that the cost of the epidemic to the government was at least $\$ 1,000,000$.

Mumps is defined by Osler as "a specific infectious disease, characterized by swelling of the salivary glands and a special liability to orchitis in males." It might be added that it is self-limited and its complications temporary and functional.

ANATOMY

Anatomic considerations should have brief mention: The parotid gland weighs from $1 / 2$ to 2 ounces. It lies below and in front of the external ear, limited above by the zygoma and below by the angle of

\footnotetext{
* Sulmitted for publication June 6, 1918.
} 
the mastoid and a line drawn horizontally from this point to the mastoid process. The external carotid artery is buried in it and the facial nerve crosses it transversely. Stenson's duct is $2 \frac{1}{2}$ inches long and opens into the mouth opposite the second upper molar. The blood supply is from the external carotid. Nerves issue from the carotid plexus of the sympathetic, fascial, and branches of auriculotemporal and great auricular.

Submaxillary Gland.-This gland weighs about 8 drams. It is placed under the lower jaw, lying on the mylohyoid, stylohyoid and hyoglossus muscles. It is separated from the parotid by the stylomaxillary ligament. The faciala artery is imbedded in a groove on the posterior surface. Its duct (Wharton's) is 2 inches long and opens at the summit of a papilla by the side of the frenum linguae. The blood supply is received from branches of the facial and lingual arteries. Nerves reach it from the submaxillary ganglion of the sympathetic and the mylohyoid branch of the inferior dental.

Sublingual Gland.-This is the smallest, weighing about 2 drams. It is placed under the mucous membrane at the floor of the mouth and is almond shaped. Its ducts (ducts of Rivinus, 18 to 20 in number) open separately on the floor of the mouth, generally one or two being joined and called Bartholin's ducts, which in turn join Wharton's duct. The blood supply is from the sublingual and submental arteries. The gustatory nerve from the posterior division of the inferior maxillary, supplies the gland.

The structure of these glands is that of the compound racemose type, joined by dense areolar tissue, ducts and vessels. The secretion is alkaline, water and contains ptyalin, which acts on the starch in food, changing it to dextrose or grape-sugar.

Pathology.-Not much is known of the pathology of mumps. The salivary glands are swollen. Of the entire series, one gland was removed on mistaken diagnosis. It showed a normal gland structure. Suppuration occurred in one case. It is questionable whether there was real gland suppuration here, or cellulitis of the tissues of the neck, with necrosis. Cervical and inguinal adenitis are not infrequent. The thyroid ${ }^{1}$ gland may become enlarged during the disease. There were six cases. None of the other features of goiter appear, however. Neurotic manifestations suggest intracranial glandular involvement. In one case, in a woman, an axillary gland was swollen, producing breast pain. The pancreas is involved in some mysterious way. It may be the seat of edema or the glands at the hilus of the liver may enlarge. Except by one or the other or both of these theoretical pos-

1. Major Sailer thinks it likely that these may have heen cases of thymus rather than thyroid involvement. They have, however, not been carefully studied, unfortunately. 
sibilities, it is difficult to explain the jaundice, abdominal pain and vomiting of pancreatitis. Orchitis is frequent. The testicles are swollen, both or one, and tender. They may each reach the size of a man's fist. The scrotum is always red and tense. Epididymitis often precedes the orchitis. A kidney bean shaped and sized swelling in the epididymis occurs sometimes before the testicle swells. Major Sailer emphasizes the fact that the epididymitis of mumps is not characterized by the exquisite tenderness which obtains in gonorrheal infection and that the testicle is very tender. Prostatitis is not common, but occurs and may be responsible for retention of urine.

TABLE 1.-Showing the Glands Involved

\begin{tabular}{|c|c|}
\hline Glands Involved: & Cases \\
\hline Both parotids alone....... & 2,747 \\
\hline Parotid, right $\ldots \ldots \ldots \ldots \ldots \ldots \ldots$ & 554 \\
\hline Parotid, left $\ldots \ldots \ldots \ldots \ldots \ldots \ldots \ldots \ldots$ & 627 \\
\hline Both submaxillaries alone........... & 16 \\
\hline 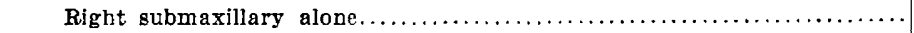 & 7 \\
\hline 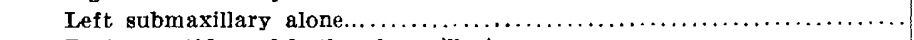 & 11 \\
\hline 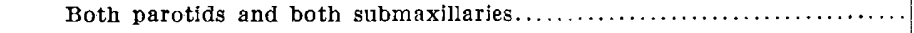 & $12 \varepsilon$ \\
\hline 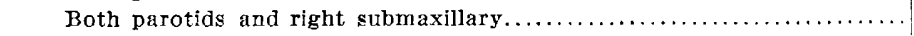 & 38 \\
\hline 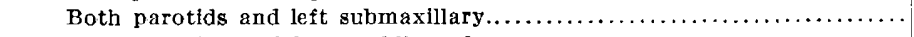 & 50 \\
\hline 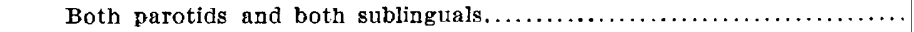 & 9 \\
\hline 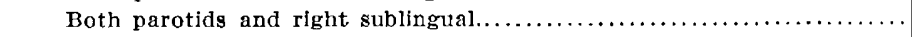 & 1 \\
\hline 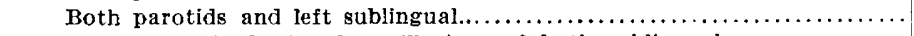 & 1 \\
\hline Both parotids, both submaxillaries and both sublinguals............... & 10 \\
\hline Both parotids, both submaxillaries and left sublingual................ & 1 \\
\hline 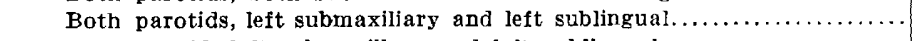 & 1 \\
\hline Left parotid, left submaxillary and left sublingual. $\ldots \ldots \ldots \ldots \ldots \ldots \ldots$ & 1 \\
\hline 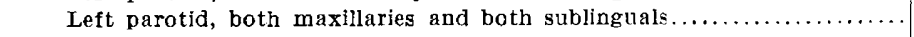 & 1 \\
\hline Right parotid, left submaxillary and left sublingual. $\ldots \ldots \ldots \ldots \ldots \ldots \ldots$ & 1 \\
\hline 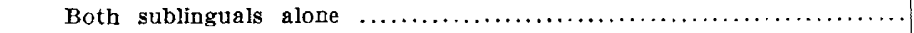 & 1 \\
\hline 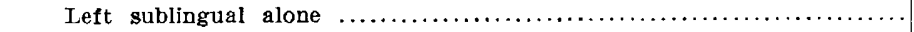 & 1 \\
\hline 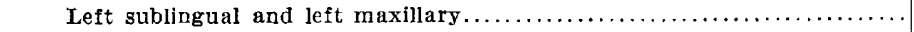 & 1 \\
\hline Right sublingual and right submaxillary $\ldots \ldots \ldots \ldots \ldots \ldots \ldots \ldots \ldots \ldots$ & 1 \\
\hline 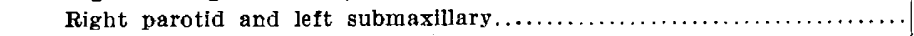 & 11 \\
\hline 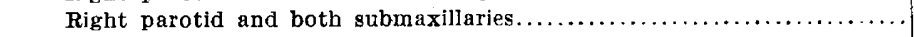 & 2 \\
\hline 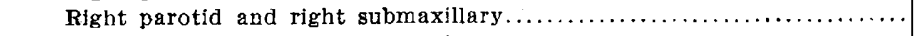 & 24 \\
\hline 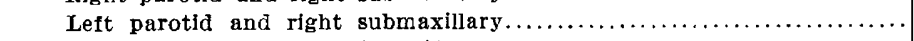 & 10 \\
\hline 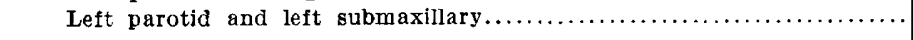 & 26 \\
\hline 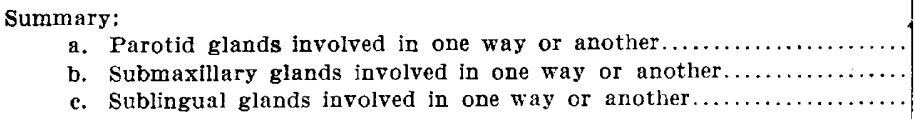 & $\begin{array}{r}4,243 \\
440 \\
30\end{array}$ \\
\hline
\end{tabular}

Finally there are a few cases in which mumps expresses itself by a general swelling of the neck and chest like Hodgkin's disease, a doughy gelatinous mass. Cases of this sort have been noted by Lieutenant Hathcock and Lieutenant Groover. There is no tenderness. The tissues are soft and elastic and are easily agitated. Major Sailer has called attention to a case of possible thymus enlargement. There was some swelling presternally and also in the tissues of the neck. There was alteration in the percussion note over the manubrium on change of position of the head, tympany being present when the 
head was drawn back and dulness when it was brought forward. The skin showed slight edema which Major Sailer attributed to cutting off the lymph supply by the inflamed thymus. Roentgenograms showed a shadow behind the upper part of the sternum, which Major Wheat interpreted as an enlarged thymus.

One case of frontal sinusitis has been recorded. It is difficult to associate this with mumps etiologically. The glands involved in our cases have been as shown in Table 1 .

Pathologic conditions associated with mumps were as shown in Table 2.

TABle 2.-Pathologic Conditions Associated with Mumps

\begin{tabular}{|c|c|c|}
\hline Condition & $\begin{array}{l}\text { At or Before } \\
\text { Onset, Cases }\end{array}$ & $\begin{array}{l}\text { Developed During } \\
\text { Onset, Cases }\end{array}$ \\
\hline Measles............ & 12 & 2 \\
\hline “Cold".......... & Very common & Very common \\
\hline Bronchitis........... & 13 & 14 \\
\hline 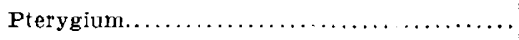 & 1 & 0 \\
\hline Influenza............ & 2 & 1 \\
\hline Laryngitıs........... & 6 & 0 \\
\hline Pnelimonia.............................. & 5 & 4 \\
\hline Bronchopneumonia.......... & 1 & 1 \\
\hline Tonsillitis.............. & 2 & 0 \\
\hline Malaria.................... & 1 & 0 \\
\hline 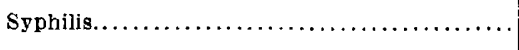 & 1 & u \\
\hline Complications of mumps.................... & \multicolumn{2}{|c|}{ To be mentioned separately } \\
\hline
\end{tabular}

Incubation Period.-This was definite in only two cases. Nurse M. was put on duty in a mumps ward January 10 and developed mumps January 24. Miss H. developed mumps February 26, having left her last case February 3. These are periods of two and three and one half weeks, respectively. Osler says that the period is from two to three weeks. In our experience, this has been generally undeterminable.

\section{E'TIOLOGY}

1. The Virus. - Thus far the causative factor of mumps has not been definitely determined. Herb has implicated a diplococcus, which, when injected into Stenson's duct in monkeys, produces the disease. Attempts at isolation of an organism were initiated at Major Sailer's suggestion. These attempts have failed. Smears from the region of the orifice of the duct in the cheek revealed a spirillum, smaller and more slender than the treponema pallidum, in a few cases. 
This was not constant, and it was concluded that the organism was the ordinary Spirochaeta dentium. Wright's tubes were next introduced into the orifice and smears made of the clear fluid which exuded, with negative results. At Major Sailer's suggestion, the parotid gland was aspirated with an ordinary hypodermic syringe, under aseptic conditions, one half inch below the ear. The few droplets of clear salivary secretion obtained in this way were planted on the following mediums : broth, plain agar, blood agar, human serum agar, Loeffler's medium, centrifugalized milk with a layer of cream on top, and agar covered with sterile liquid petrolatum - the last two being partially anaerobic. The results in all cases were negative, except on one occasion in which a pellicle was produced in ordinary bouillon, which showed very small cocci in flat masses. This was not reproducible, and it was concluded that the pellicle was the ordinary one which at times occurs in broth without inoculation. Smears from aspirated contents of the glands were negative. Major Sailer was very desirous of inoculating the testes of animals with the secretion, but, unfortunately, none were to be obtained. Major Thayer, on a visit to Camp Wheeler, suggested the use of salivary mediums for culture. This too, unfortunately, was not tried, due to press of work in the laboratory. It is an excellent idea and should be exploited. Noguchi's symbiotic tissue medium was not used because it could not be obtained. At my request a few tubes of 2 per cent. glucose agar and human serum were sent down by Dr. Libman from New York. Two thirds of the agar were mixed with one third serum (after melting the agar) and the tubes innoculated with the secretion aspirated from the parotid gland, and also with the blood of a patient who had developed orchitis. The tubes were rendered anaerobic by the addition of a layer of plain agar, on cooling of the mass. These ingredients were used by Dr. Plotz in isolating the organism in his typhus work. Four days after inoculation no results had appeared. ${ }^{2}$ It is to be concluded therefore that the virus does not grow on ordinary mediums. Inoculations intraperitoneally into mice and guinea-pigs by Lieutenant Lewis of the aspirated contents of the parotid were negative. Thanks are due and gladly given to Captain Wilson and Lieutenant Ross for their kindness and assistance in the laboratory.

2. Contact.-There must necessarily be some influence exerted on the development of mumps by contact; otherwise the epidemic would not occur, and yet of the physicians, nurses and corps men, only

2. On the sixth day a lenticular colony, grayish yellow in color, about the size of a millet seed appeared in the middle of the medium. There were fine ciliary radiations from it. Smears showed diplococci which will be described subsequently. 
twenty-nine all told took the disease-persons who had been in intimate contact with it. Five were nurses, five physicians, and nineteen corps men, of whom four were not Base Hospital men, but belonged to ambulance companies.

3. Age.-The age incidence was from 16 to 25 years.

4. Sex.-Only five cases were in women. (Eighty nurses in hospital were the only material.)

5. Service.-The length of service in 95 per cent. of the cases was two months.

6. Habitat.-The fact that most of the men lived on farms nearly all their lives may have had some bearing on the epidemic. They had not been accustomed, like their urban cousins, to epidemics of any sort, and therefore, from lack of immunity, geographically furnished good soil for the virus.

8. Previous Condition.-A factor of some importance was the previous condition of the men. They had been below par physically.

7. Season.-The winter months, October to March, were included.

9. Immunity.-One attack does not confer immunity. Forty-seven patients gave a previous history of mumps, in the majority of which cases the gland on the side opposite to that of the present attack had been involved; but three patients had the same gland involved twice. One patient had mumps three times. The intervals varied from two weeks to fourteen years. Lieutenant Hathcock doubts these histories and claims that one attack protects. One hundred and forty-four cases, or 3.3 per cent., had more glands develop during course than were involved at onset. The majority were right and left parotids, respectively. The intervals varied from one to seventeen days; the average was nine days, most frequently only twenty-four hours. Relapses occurred in six cases. The interval was from two to three weeks.

\section{SMPTOMS}

The symptoms of mumps show many varied but also some constant features.

1. Prodromal.-Often a diagnosis of mumps may be reached before there is any swelling from the following symptoms:

a. A feeling of stiffness in the jaws.

b. Difficulty in opening mouth.

c. Condiments, especially sour ones, cause a "drawing" sensation in the jaws.

$d$. Dry mouth may occur at first. No sense of taste and no secretions. There may be salivation. Thirst is at times unquenchable. 
$\epsilon$. The orifices of Stenson's duct pout and a pinkish area appears around them. They may gape wide open. This is especially notice. able in unilateral cases. A Wright's tube is introduced with ease, whereupon a clear fluid fills it.

$f$. The most diagnostic prodromal sign, pathognomonic, in fact, was first noted by Lieutenant Hathcock, who has personally observed and treated over 2,000 cases, and who is, from the standpoint of knowledge gained by close clinical observation of the disease, probably the best authority on mumps in the United States. The sign is tenderness just beyond the angle of the jaw on running the finger toward the angle, under the mandible. If the parotid gland is at all involved, the patient winces with pain. This occurs before any swelling can be made out. It is proper and fitting -- much as eponyms are held by some to be improper - that this sign go down in the literature as Hathcock's sign. It is almost constant, it is early, it is definite and it is exclusive; therefore it is diagnostic, like Koplik's spots in measles.

2. The Onset.-The symptoms of onset of mumps have been many and varied.

a. Onset with no symptoms.

b. Onset with gastric disturbances and features suggesting pancreatitis.

c. Onset with pancreatitis, orchitis and urethral discharge. This occurred in two cases before the glands swelled. Lieutenant Byrne has seen one of them.

$d$. Onset with features of acute laryngitis and bronchitis. This was rather common in Lieutenant Hislop's series. It was especially marked during the time when measles and mumps coexisted. Cough was a marked feature. Also pain in the sternal region.

e. Grippy onset, with fever, headache, malaise, bone pains and aches, and sore throat was very common.

$f$. Onset with inguinal and testicular pain and backache - although orchitis did not develop - was not infrequent.

$g$. The ordinary onset is with pain and swelling in the jaws, stiffness, difficulty in opening the mouth, slight malaise and mild fever. According to Lieutenant Hathcock, the pain in parotid cases is greater than in submaxillary cases, because of the proximity of the tissues to the bone in the former and to the soft elastic tissues of the neck in the latter case.

3. The Course.-This is variable. Special symptoms of all sorts arise. Elevation of temperature is not constant; fever occurred in over 80 per cent. of the cases, however (Figs. 1 and 2). 
The temperature in all cases showed a rise and fall in severity, corresponding to the epidemic proper. The range of fever is from 99 to $106 \mathrm{~F}$., most commonly 99 to 101 . The duration of the fever is from one to twenty-four days; the average is four days. About twenty-four hours before onset of a complication the temperature rises from one to three degrees and lasts about five days. Subnormal

\begin{tabular}{|c|c|c|c|c|c|c|c|}
\hline Days & \begin{tabular}{|l|l}
1 & 2 \\
\end{tabular} & \begin{tabular}{|l|l|}
2 & 3 \\
\end{tabular} & \begin{tabular}{|l|l}
4 & \\
\end{tabular} & \begin{tabular}{l|l}
5 & 1 \\
\end{tabular} & 6 & 7 & 8 \\
\hline 106 & & & & & & & \\
\hline 104 & & & & & & & \\
\hline 102 & & & & & & & \\
\hline 100 & & & & & & & \\
\hline 98 & 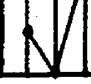 & & & & & & \\
\hline
\end{tabular}

Fig. 1.-Temperature curve in an ordinary case.

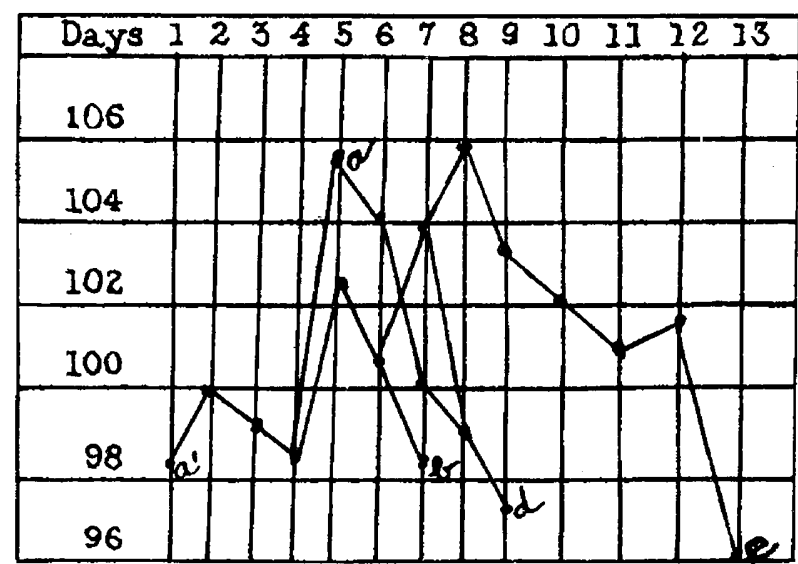

Fig. 2.-Temperature curve in orchitis accompanying mumps: $a^{\prime}-b$, most common; a-e, all occur.

temperature may occur with cessation of the complication. The temperature may be $106 \mathrm{~F}$. without obvious cause.

Vomiting, nausea, and pain and tenderness in the testicles may occur without apparent cause.

Tenderness in the epigastrium, jaundice and vomiting suggest pancreatitis.

Urinary retention may develop. Lieutenant Urey removed 32 
ounces by catheter in one case. Sometimes prostatitis is associated with retention. Lieutenant Hislop is of the opinion that retention is reflex from the pain in the testicles and lumbar regions. Polyuria is not common.

Tender breasts occurred in one man and in one woman.

The patient may be doing well, apparently, and without cause develop the most marked nervous disturbances. Fainting, cold sweats, sense of collapse, diarrhea and excessive irritability may occur. Convulsions are rare, only one patient presenting a few jerky movements.

TABLE 3.-PERCENTAGES

\begin{tabular}{|c|c|c|c|c|c|c|c|c|}
\hline \multirow{2}{*}{ Cases } & \multirow{2}{*}{$\begin{array}{c}\text { Poly- } \\
\text { morpho- } \\
\text { nuelears }\end{array}$} & \multicolumn{2}{|c|}{ Lymphocytes } & \multicolumn{2}{|c|}{ Endothelials } & \multirow{2}{*}{$\begin{array}{l}\text { Eosino- } \\
\text { phils }\end{array}$} & \multirow{2}{*}{$\begin{array}{c}\text { Baso- } \\
\text { phils }\end{array}$} & \multirow{2}{*}{$\begin{array}{l}\text { Total } \\
\text { Count }\end{array}$} \\
\hline & & Small & Large & Trans. & Others & & & \\
\hline Normal (Stitt).... & 67.5 & 25.0 & 4.0 & 3.0 & 1.5 & 1.5 & 0.4 & 7,125 \\
\hline Orchitis.............. & 60.2 & 30.2 & 4.3 & 1.7 & 1.8 & 1.8 & $\cdots$ & 10,730 \\
\hline Uncomplicated.... & 51.9 & 36.4 & 2.0 & 3.1 & 3.0 & 3.6 & $\ldots$ & 7,060 \\
\hline Average (all cases).. & 54.2 & 34.7 & 2.6 & $2 . \overline{7}$ & 2.7 & 3.1 & $\ldots$ & 8,060 \\
\hline
\end{tabular}

TABle 4.-Total Cells Per Cubic Millimeter

\begin{tabular}{|c|c|c|c|}
\hline & Orchitis & Uncomplicated & Total \\
\hline 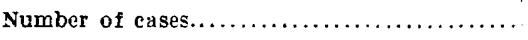 & 3 & 8 & 11 \\
\hline Total leukocytes....................... & 10,730 & 7,060 & 8,060 \\
\hline Polymorphonuclears.............. & 6,470 & 3,660 & 4,390 \\
\hline 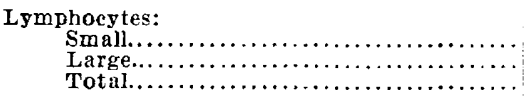 & $\begin{array}{r}3,240 \\
460 \\
3,700\end{array}$ & $\begin{array}{r}2,570 \\
140 \\
2,710\end{array}$ & $\begin{array}{r}2,806 \\
210 \\
3,010\end{array}$ \\
\hline 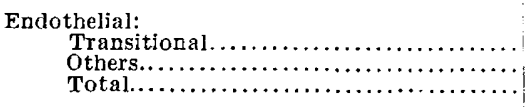 & $\begin{array}{l}180 \\
190 \\
370\end{array}$ & $\begin{array}{l}220 \\
210 \\
430\end{array}$ & $\begin{array}{l}210 \\
200 \\
410\end{array}$ \\
\hline 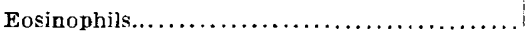 & 190 & 260 & 240 \\
\hline
\end{tabular}

All grades of deafness have been present. One patient described his ears as "wooden." Rarer symptoms, but occurring in a sufficient number of cases to warrant their notice, were epistaxis, herpes and dysphonia. A husky or small voice was most frequent.

4. Laboratory Findings.-The blood was examined in about 200 cases. Of 105 white counts made by Lieutenant Lewis, the average figure was 8,800 , the extremes being 6,000 and 13,000 . The accompanying tables and curves show the results obtained by Lieutenant Belding's blood counts in mumps (Tables 3, 4 and 5). 
Lieutenant Beiding concludes:

1. Total Count.-The uncomplicated cases showed approximately a normal total leukocyte count $(7,060)$. In orchitis, there is a definite leukocytosis $(10,730)$, which is largely polymorphonuclear in character, that is, 6,470 polymorphonuclear cells per cubic millimeter, nearly double the number $(3,660)$ in the uncomplicated cases; whereas the lymphocytes show a smaller increase, that is, 3,240 vs. 2,570 , or a corresponding gain of one quarter.

TABle 5.-Number and Percentage of Cells

\begin{tabular}{|c|c|c|c|}
\hline & Orehitis & Uncomplicated & Total \\
\hline Number of cases.............................. & 3 & 8 & 11 \\
\hline 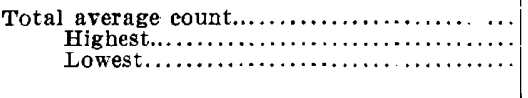 & $\begin{array}{r}10,730 \\
14,000 \\
7,400\end{array}$ & $\begin{array}{r}7,060 \\
12,700 \\
4,030\end{array}$ & $\begin{array}{r}8,060 \\
14,000 \\
4,080\end{array}$ \\
\hline 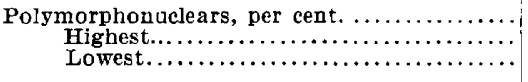 & $\begin{array}{l}60.2 \\
82.0 \\
46.4\end{array}$ & $\begin{array}{l}51.9 \\
61.5 \\
41.0\end{array}$ & $\begin{array}{l}54.2 \\
82.0 \\
46.4\end{array}$ \\
\hline 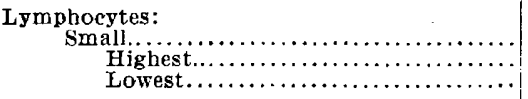 & $\begin{array}{l}30.2 \\
40.6 \\
11.0\end{array}$ & $\begin{array}{l}36.4 \\
50.0 \\
27.0\end{array}$ & $\begin{array}{l}34.7 \\
50.0 \\
11.0\end{array}$ \\
\hline 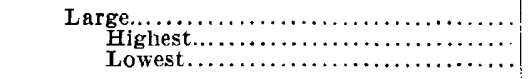 & $\begin{array}{l}4.3 \\
8.0 \\
2.0\end{array}$ & $\begin{array}{l}2.0 \\
4.0\end{array}$ & $\begin{array}{l}2.6 \\
8.0\end{array}$ \\
\hline 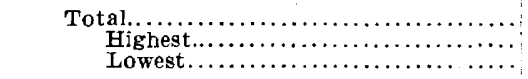 & $\begin{array}{l}34.5 \\
43.6 \\
13.0\end{array}$ & $\begin{array}{l}38.4 \\
51.0 \\
27.7\end{array}$ & $\begin{array}{l}37.3 \\
51.0 \\
13.0\end{array}$ \\
\hline 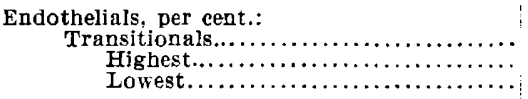 & $\begin{array}{l}1.7 \\
3.0 \\
1.0\end{array}$ & $\begin{array}{l}3.1 \\
4.0 \\
2.0\end{array}$ & $\begin{array}{l}2.7 \\
4.0 \\
1.0\end{array}$ \\
\hline 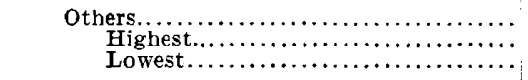 & $\begin{array}{l}1.8 \\
4.0 \\
\cdots\end{array}$ & $\begin{array}{l}3.0 \\
7.0 \\
1.0\end{array}$ & $\begin{array}{l}2.7 \\
7.0\end{array}$ \\
\hline Total............... & 2.5 & 6.0 & 5.4 \\
\hline 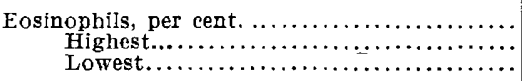 & $\begin{array}{l}1.8 \\
5.5 \\
\cdots\end{array}$ & $\begin{array}{l}3.6 \\
6.0 \\
1.0\end{array}$ & $\begin{array}{l}3.1 \\
6.0\end{array}$ \\
\hline
\end{tabular}

2. Polymorphonuclear Neutrophils.-The polymorphonuclear leukocytes show a relatively higher percentage in the orchitic than in the uncomplicated cases. In the latter, the average (51.9 per cent.) is somewhat less than the normal (67.5 per cent.) as given by Stitt. In the orchitic cases, the percentage of polymorphonuclears is 60.2 , which is less than is ordinarily found with leukocytosis of pyogenic infections.

3. Lymphocytes.-Conversely, the relative percentage of lymphocytes, 38.4 per cent. in uncomplicated and 34.5 per cent. in orchitic cases, is above the normal, which varies from 22 to 36 per cent. The highest orchitis case gave 43.6 per cent., the lowest 13 per cent. ; while 
in the simple cases the highest was 51 per cent. and the lowest 27.7 per cent. Therefore, it may be concluded that there is a slight tendency toward lymphocytosis in mumps, but in view of the small number of cases here considered (11) a definite statement cannot safely be made when the margin of increase is so small.

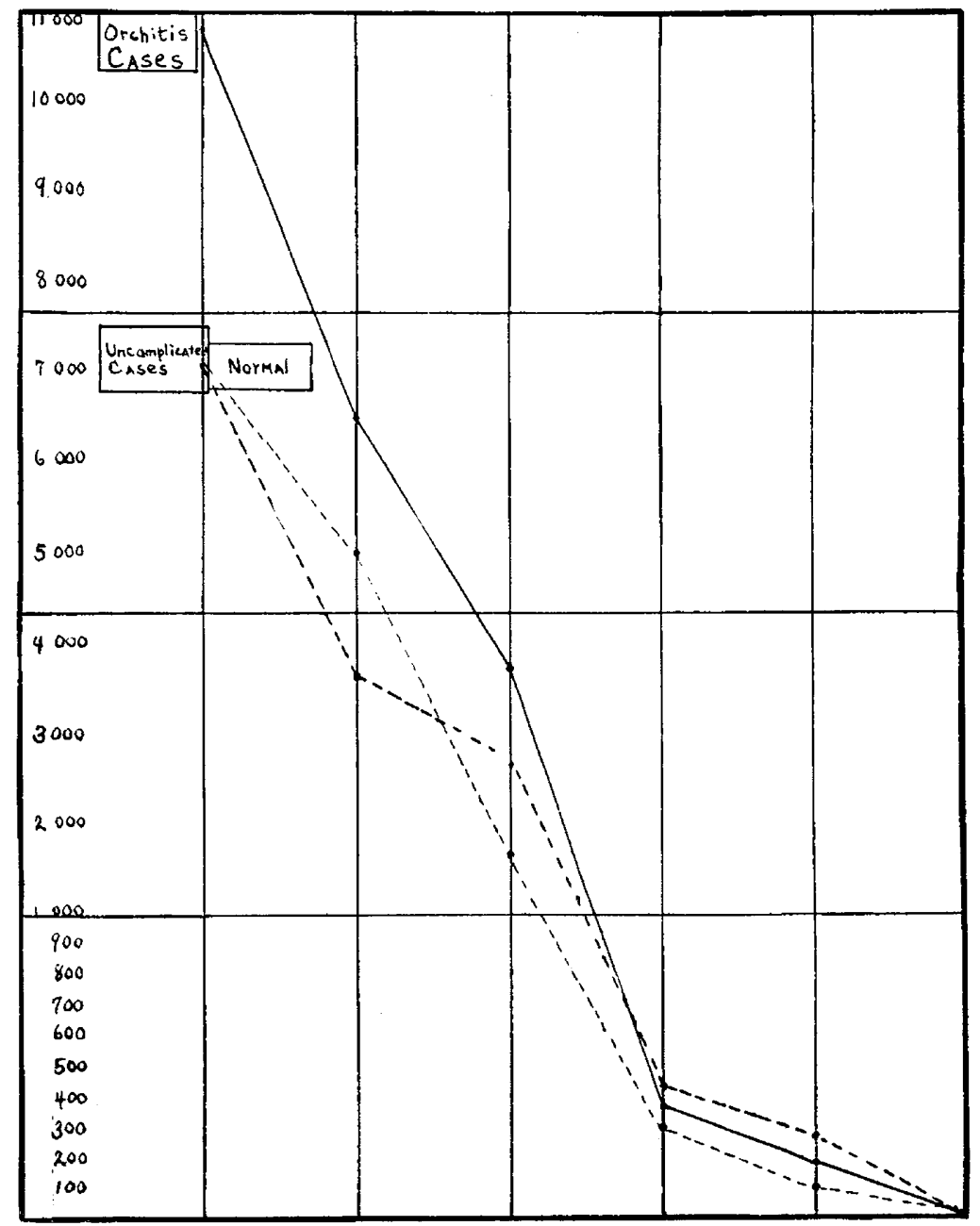

Fig. 3.-Curves showing leukocyte and differential count in mumps uncomplicated (eight cases), and in cases complicated by orchitis (three cases), from Feb. 7, 1918, to Feb. 18, 1918.

4. Endothelials.-This class gives a slight increase above the average, but falls within normal limits.

5. Eosinophils.-The increase in eosinophils is probably due to intestinal parasites (hookworm) and has nothing to do with mumps. 
Red blood cells averaged 4,800,000; average hemoglobin 75 per cent. The urine in thirty cases - all kinds - was normal. Bile was present in one case of pancreatitis with jaundice, which cleared up on disappearance of the icterus. (Lieutenant Lewis.)

5. The Physical Signs of Mumps:

1. Hathcock's sign.

2. Pouting and pinkness of the orifices of Stenson's ducts.

3. Swelling of the face in the parotid region.

4. Doughy elasticity of the swelling.

5. Exudation of secretion from Stenson's duct on pressure of the gland externally. This was noted by Lieutenant Hathcock and others. The physical examination of the rest of the body is usually negative except in complicated cases.

\section{COMPLICATIONS}

1. Orchitis and Epididymitis.-Of 4,397 cases carefully considered, 611 had testicular involvement of various kinds, or 13.91 per cent.

TABLE 6.-CoMplications

\begin{tabular}{|c|c|}
\hline Complieations & Number of Cases \\
\hline Orchitis, bflateral....... & 102 \\
\hline Orchitis, right............................... & 231 \\
\hline Orchitis, left............................. & 221 \\
\hline Orchitis, side not mentioned............................ & 40 \\
\hline Epididymitis, right......................... & 4 \\
\hline 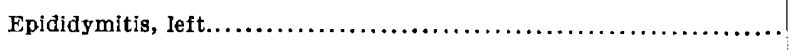 & 1 \\
\hline 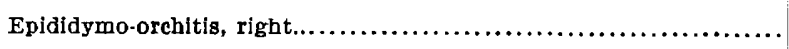 & 9 \\
\hline 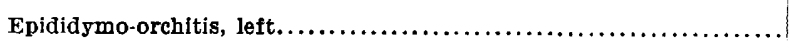 & 3 \\
\hline Total... & 611 \\
\hline
\end{tabular}

Perhaps epididymitis was more common than this table indicates, because of the fact that the ward surgeons did not pay special attention to the orchitis cases beyond noting that the testicles were involved.

Thirty-seven cases developed orchitis on the side opposite to the glandular involvement of the face. Close questioning in many similar cases revealed a former infection on the other side of the face also. It is the general impression held by the ward surgeons that these thirtyseven cases may fall in this category. At any rate, the vast majority had the testicles involved on the same side as the facial swelling in unilateral cases.

Orchitis is the most frequent and most severe complication of mumps. It may occur in any period of the disease, even before the 
parotid swelling, and be accompanied by urethral discharge. Orchitis begins from the third to the sixth day and lasts a variable period from five to ten days. In not a few cases the epididymis is swollen before the testicles. Single glandular involvements were complicated by bilateral orchitis and vice versa. Orchitis makes the patients sick. There is a rise in temperature sometimes to $106 \mathrm{~F}$., usually to 102 . Vomiting and nausea are frequent. The patient may be covered with profuse warm perspiration. The face is anxious. Sharp shooting pains in the testicles and inguinal regions occur. There may be severe backache. With the rise in temperature, a leukocytosis is usually present from 11,000 to 14,000 , as shown by Lieutenant Belding and Lieutenant Lewis. Polyuria may be present. Lieutenant Dalton has obtained histories of nocturnal pollutions in these cases which he believes are due to reflex irritations. Lieutenant Hathcock, on the other hand, thinks that continence is responsible for the condition. At any rate, close observation of this symptom has not shown it to be a constant feature. After a miserable period of from twenty-four to forty-eight hours, the testicles enlarge and are exquisitely tender. The course of orchitis is variable. After three to ten days, the testicles involute, the fever subsides, the pain and malaise depart, urination is free, the appetite returns and the patient is to be found more frequently at the canteen than in the ward.

2. Otitis Media.-Suppurative otitis media occurred in 20 cases of 4,397 , or 0.45 per cent.

TABLE 6.-EAR INVOLVEMENT

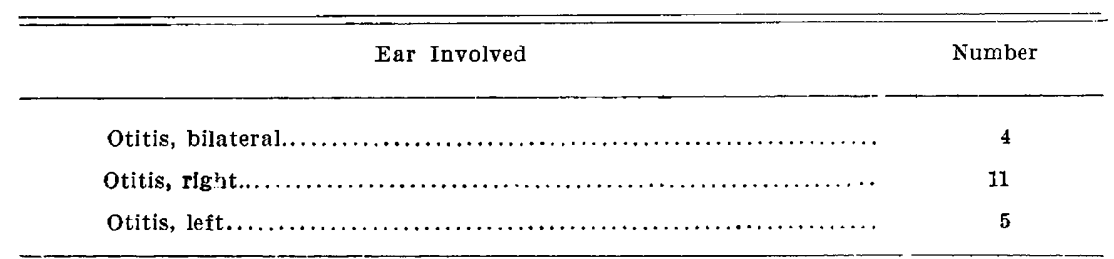

Suppuration may be profuse or mild. Pain is of varying degree of intensity. There is a rise in temperature of several degrees and at times dysphonia - nasal voice occurs. Fainting and vertigo may come on. Mastoiditis occurred in three cases which were not recorded among the total number, and were operated on by Captain Swan.

3. Pancreatitis.-Whether an entity or a syndrome, the symptom group is real. The patient becomes extremely ill. There is intense nausea and anorexia. Pain and tenderness in the epigastrium rapidly supervene. The temperature rises slightly. Diarrhea may occur or the patient may become jaundiced, four cases of this kind having been noted. The spleen was palpable in one case, but the patient gave a malarial history. The attack is like acute catarrhal jaundice, except 
that it lasts only from three to five days. Pancreatitis occurs from the fifth to the eighth day, as a rule, but this varies. There were fourteen cases, or 0.31 per cent.

4. Pneumonia.-Five cases of lobar and one case of bronchopneumonia occurred during mumps. Major Sailer feared an increased pneumonia admission rate as a result of mumps, just as happened after measles, but fortunately this did not occur. Mumps has apparently little effect on the respiratory system from the standpoint of lowering the resistance to pneumonia.

5. Bronchitis.-There were nine cases of the ordinary type and course.

SEQUELAE

It is premature to note any sequelae in our epidemic. Sexual vigor is retained according to Osler, even with both testicles atrophied. It is not definite whether permanent deafness results from the otitis media.

DIAGNOSIS

The diagnosis of mumps is the simplest to make, and in mild cases very easy to overlook. The following are diagnostic:

1. Hathcock's sign.

2. Pink and pouting orifices of Stenson's ducts.

3. Swelling and tenderness of the salivary glands.

4. Exudation of secretion from duct on pressure of gland.

5. Pain or peculiar "drawing" sensation on eating sour food.

Differential Diagnosis:

1. Parotids enlarged.

Ordinary Toothache with

Mumps
enlarged. Ordinary Toothoch
Edema

2. Hathcock's sign positive. 1. Parotid not enlarged.

3. May be dry mouth. 2. Negative.

4. Gums not swollen.

3. May be salivation.

5. Perverted taste and pain if sour food is eaten.

4. Gums swollen.

5. Neither.

1. Fever.

Mumps

1. None. Epulis

2. Gums O. K.

2. Tumor.

3. Parotids swollen.

3. Not swollen.

4. Epidemic.

4. Not epidemic.

Submaxillary Mumps

1. Epidemic.

Tonsillitis with Cervical Glands

2. Tonsils normal.

1. Not epidemic.

3. Swelling is under center of mandible.

2. Inflamed.

3. Further back. 
Course of Disease.-In uncomplicated cases, in a week the infection has subsided. The average duration - all cases - has been fourteen days; limits, two to thirty-one days. A complication prolongs the course about a week. A normal patient may suddenly develop orchitis or otitis. If pancreatitis occurs, the course is prolonged about four days. Pneumonia and bronchitis lengthen the disease by their own course.

PROGNOSIS

Of the entire epidemic, the only death was due to pneumonia. Complications are temporary. A patient without facial swelling who presents Hathcock's sign and pouting orifices of Stenson's duct will develop mumps. If, on the third day, the patient has a rise in temperature, pain in testicles, abdomen and back, with vomiting and perspiration, he may develop orchitis or pancreatitis or both. Deafness does not mean otitis. Mastoiditis has the same prognosis as in any other condition.

\section{TREATMENT}

A. Prophylaxis.-1. Careful isolation of cases for a period covering their infectivity - three weeks.

2. Of orchitis: Orchitis occurred no more frequently in the series studies by Lieutenant Byrne and Lieutenant Sherrill, whose patients got up for meals and walked about generally, than it did in Lieutenant Groover's series, whose patients stayed in bed throughout the course. Lieutenant Lewis has found that careful sterilization of the hands and protection of the glans penis did not reduce the incidence of the complication. At Major Sailer's suggestion, alternate patients were put on hexamethylenamin as admitted, 5 grains four times daily. Lieutenant Hathcock's figures show no improvement after the drug, and he concludes that "hexamethylenamin produces no perceptible results as to prevention of orchitis." Considering all figures, however, there is some benefit. Before the exhibition of hexamethylenamin, 304 cases occurred and 307 afterward, but there were only 52 cases of orchitis in which the hexamethylenamin was given before the patient had orchitis - a reduction in number by 33 per cent.

3. Of otitis: Of all measures, 2 per cent. phenolized glycerin instituted routinely - drops 2 being dropped into each nostril twice daily - at Major Sailer's suggestion, has proved the most beneficial. Before phenol in glycerin treatment began, there were seventeen cases; afterwards but three.

B. Treatment Proper.-The treatment proper of mumps is palliative, symptomatic and expectant. Our treatment has been:

1. Two compound cathartic pills on night of admission and saline in morning to insure free catharsis. 
2. Dobell's gargle for mouth.

3. Hot application and camphorated oil to swelling.

4. For the pain and nervousness, acetyl salicylic acid and bromids.

5. For fever, acetyl salicylic acid and acetanilid.

6. Phenol, 2 per cent. in glycerin, 2 drops in each nostril, should be administered twice daily.

7. Hexamethylenamin has some value in reducing the incidence of orchitis; 5 grains four times daily.

8. For orchitis, support and counterirritation; any mild counterirritant will do: $a$. ice bag; $b$. 10 per cent. icthyol ointment; $c$. guaiacol carbonate was used in a few cases with fair results; and finally,

9. Rest in bed, which is the best treatment. 